Bosch, M.A. 184

Cardoso, R.C. 226

Choe, H.K. 194

Chun, S.K. 194

Dhillo, W.S. 238

Fuller, E.A. 216

Giacobini, P. 200

Hodgson, D.M. 216

Kelly, M.J. 184

Kim, D. 194
Kim, H.-D. 194

Kim, J. 194

Kim, K. 194

Millar, R.P. 181

Padmanabhan, V. 226

Prague, J.K. 238

Puttabyatappa, M. 226

Rønnekleiv, O.K. 184

Sominsky, L. 216

Zhang, C. 184

\title{
Subject Index Vol. 102, No. 3, 2015
}

Androgens 226

Biological rhythm 194

Canonical transient receptor potential channels 184

Cell migration 200

Development 200

Dynamic transcription 194

Estrogens 226

Fertility 226

GnRH pulse generator 194

Gonadotropin 238

Gonadotropin-releasing hormone 184, 200
Hyperpolarization-activated, cyclic nucleotide-gated current 184

Inflammation 216

Insulin 226

Kisspeptin 184, 194, 238

Lipopolysaccharide 216

Neuronal plasticity 200

Novel therapies 238

Perinatal programming 216 Persistent sodium current 184

Polycystic ovary syndrome 226

Reproduction 200

Reproductive development 216

T-type calcium current 184 